\title{
SocializaCión DE CONOCIMIENTOS DEL CAFÉ ORGÁNICO EN EL CONTEXTO DE ESPACIOS COLECTIVOS \\ DE GRUPOS LOCALIZADOS DE PARENTESCO TSELTALES, Tenejapa, Chiapas
}

\section{Socialization of knowledge of organic coffee in the context of collective spaces of localized groups of kinship tseltales, Tenejapa, Chiapas}

\author{
Edith Cervantes Trejo* \\ ERIN ESTRADA LUGO**
}

\section{RESUMEN}

El objetivo de este trabajo es comprender que la práctica de socialización de conocimientos requiere considerar los contextos en que esta se realiza. Entre estos contextos se encuentran las propiedades de los espacios que son escenarios de esa práctica social. La metodología empleada consistió en la indagación de las propiedades de los espacios en donde grupos localizados de parentesco tseltales realizan esta práctica, y en la exploración de la manera en que estos grupos socializan los conocimientos acerca del café orgánico a partir del uso de esquemas interpretativos que emplean en el habla, en el marco de un saber mutuo contextualizado en la cultura tseltal. Entre los hallazgos de la investigación, destaca que el uso de sedes colectivas por los miembros del grupo y de un lenguaje que sugiere orientar y acompañar al actor que aprende favorece la difusión amplia de conocimientos del café orgánico. Esta situación revela la importancia del parentesco en la socialización de conocimientos en comunidades indígenas.

Palabras Clave: escenarios de interacción, Socialización de Conocimientos, enseñanzaAPRENDIZAJE, ESQUEMAS INTERPRETATIVOS, SABER MUTUO.

* El Colegio de la Frontera Sur, Unidad San Cristobal, Doctorado en Ciencias en Ecología y Desarrollo Sustentable.Correo electrónico: ecervantes@ecosur.edu.mx.

** El Colegio de la Frontera Sur, Unidad San Cristobal, Departamento de Agricultura, Sociedad y Ambiente. Correo electrónico: eestrada@ecosur.mx. 


\section{Abstract}

The objective of this paper is to understand that the practice of socialization of knowledge requires consideration of the contexts in which it is performed, including the properties of the spaces involved as scenarios in this social practice. The methodology used was to investigate the properties of the spaces in which localized tseltal kinship groups perform this practice and to explore how these groups the socialization of knowledge of organic coffee from the use of interpretive schemes used in speech, in the framework of a mutual know contextualized in the Tseltal culture. Among the findings of the research highlights that the use of collective action by the members of the group and of a language that suggests guide and accompany the actor who learns encourages the wide dissemination of knowledge of organic coffee. This situation reveals the importance of kinship in the socialization of knowledge in indigenous communities.

KEYWORDS: INTERACTION STAGE, SOCIALIZATION OF KNOWLEDGE, TEACHING-LEARNING, INTERPRETATIVE DIAGRAM, MUTUAL KNOW.

Recepción: 10 de febrero de 2016.

Dictamen 1: 2 de mayo de 2016.

Dictamen 2: 30 de agosto de 2016. 


\section{INTRODUCCIÓN}

Después del maíz, el café es el cultivo con mayor importancia cultural, económica, social y política en la historia nacional, a pesar de que no es un cultivo originario de México (Pérez Grovas et al., 2002, p. 29). El café se introdujo en las regiones indígenas durante la década de 1970, a partir de la promoción institucionalizada de la caficultura en este país por parte del Instituto Mexicano del Café (Inmecafé), organismo que desapareció en 1989, pero que durante su funcionamiento realizó una introducción masiva de este cultivo en las zonas montañosas del sureste mexicano, las más aptas para su desarrollo, y asiento de numerosos pueblos indígenas (Nolasco, 1985, p. 93; Pérez Grovas et al., 2009, pp. 33).

La producción del café orgánico en México es de suma importancia porque contribuye al mantenimiento de la biodiversidad, a la conservación de suelos y cuencas hidrológicas y a la mejora de la calidad de vida de quien lo produce (Boege, 2008; Moguel y Toledo, 1999). Son las organizaciones de pequeños productores de café de áreas indígenas las que sostienen este tipo de producción, que además ha posicionado a este país como el mayor productor de café orgánico en el mundo (Pérez Grovas et al., 2009, p. 37). Sin embargo, han sido escasas las investigaciones sobre los mecanismos que opera el tejido social indígena para sustentar tal diversidad de fenómenos. Además, no ha sido relevante para los estudios abocados al conocimiento de la caficultura en México, la indagación de los procesos de socialización de conocimientos del café orgánico que fomentan la organización cafetalera, y cómo estos operan en el interior de las comunidades indígenas y se entrelazan con el parentesco. La socialización y la difusión de conocimientos en áreas campesinas e indígenas se han considerado generalmente como actos de individuos o productores, con lo cual se han excluido los mecanismos del tejido social que subyacen en dichos procesos. Desde esta perspectiva se conceptúa la difusión de conocimientos a partir de la acción individual y autónoma del productor como agente de cambio, postura muy generalizada, por ejemplo, en prácticas de innovación tecnológica bajo modelos del productor-experimentador, ${ }^{1}$ el agricultor primero y último, el extensionista campesino, el productor líder, etcétera. La amplia cobertura social y territorial que caracteriza a la organización cafetalera indígena difícilmente puede explicarse con base en acciones individuales.

\footnotetext{
1 El productor-experimentador es considerado como "un agente de cambio que tiene como contacto (externo) al investigador, que aplica la nueva tecnología trasferida por éste, la valida en su terreno, y los vecinos, al ver los resultados, imitarán o aceptaran esa tecnología" (Mata, 2003, p. 85).
} 
El presente artículo explora los mecanismos sociales que operan en la socialización de conocimientos del café orgánico en el interior de comunidades cafetaleras y que posibilitan la amplia difusión de este cultivo. Se realiza una aproximación a este proceso que responde a la siguiente pregunta: ¿cómo grupos de parentesco adscritos a una organización cafetalera del área tseltal de la región de Los Altos de Chiapas realizan esta práctica de socialización? Se destaca también la importancia de tomar en cuenta el contexto de interacción de socialización de conocimientos, referido a las propiedades de los espacios en donde esta ocurre. El nexo entre el entramado del tejido social indígena y la novísima producción orgánica devela rasgos de contemporaneidad de los pueblos originarios tseltales, los cuales conforman uno de los dos grandes bloques lingüísticos mayances que forman la región alteña. En particular, el área tseltal se extiende hacia parte de las regiones de las montañas marginales del este y norte de Chiapas.

Se exponen los resultados de la investigación de dos grupos de parentesco miembros de la organización cafetalera tseltal denominada Productores de Café Orgánico de Kotolté, ubicados en las comunidades de Kotolté y Los Mangos, del municipio de Tenejapa, Chiapas, dos de las cuatro comunidades de su área de influencia. Esta organización se constituyó legalmente en 2006, y realiza la comercialización colectiva de café orgánico a través de la Unión de Ejidos San Fernando, cuya sede está en la localidad Zoque y municipio del mismo nombre, en el estado de Chiapas. El grupo de parentesco de nuestro interés constituye una unidad social intermedia ubicada entre la familia y la comunidad, formada por tres generaciones de lazo patrilineal, los padres, los hijos casados y su descendencia, que habitan un complejo habitacional en un área circunscrita. Este tipo de grupos ha sido observado empíricamente en la región alteña (Villa Rojas, 1992; Vogt, 1966; Collier 1976, Ixtacuy, et al., 2006) y en el área mesoamericana (Nutini, 1976; Robichaux, 2005), y aquí se le denomina grupo localizado de parentesco (Robichaux, 2005, pp. 168 y 172). Este grupo de parentesco se concibe como un sistema de interacción social. Por sistema se entiende "las relaciones reproducidas entre actores y colectividades organizadas como prácticas sociales regulares” (Giddens, 2011, p. 61), y la práctica situada de socialización de conocimientos del café orgánico, como una interacción social.

La investigación se enmarca en la validez del estudio de caso como método de análisis de los fenómenos sociales, en el que "un estudio de caso es una indagación empírica que investiga un fenómeno contemporáneo — el 'caso'—en profundidady en el contexto de la vida real, especialmente cuando los límites entre el fenómeno y el 
contexto no son claramente evidentes" (Yin, 2009, p. 16). En el primer apartado se abordan los espacios de residencia y productivos del grupo; cada espacio se considera como sede, es decir, como el lugar de un conglomerado amplio de interacciones entre los miembros del grupo- en el curso de un día característico, el cual presenta diferentes usos del espacio que proveen, a la vez, escenarios de interacción (Giddens, 2011, pp. 151-152). Los escenarios de interacción que intervienen en la práctica de socialización de conocimientos se distinguen por ser espacios abiertos en donde ocurren con mayor sistematicidad circunstancias de copresencia entre miembros del grupo de diferente nivel generacional, en los cuales se favorece la interacción enseñanza-aprendizaje de múltiples conocimientos, entre estos, los del café orgánico.

El segundo apartado introduce a la comprensión de la práctica de socialización de conocimientos en grupos localizados de parentesco adscritos a una organización cafetalera. Se analizan los conceptos o esquemas de comprensión manipulados por los actores miembros del grupo en los discursos producidos en la interacción enseñanza-aprendizaje de conocimientos del café orgánico, insertos en los cuerpos de conocimientos compartidos de hablantes de lengua tseltal. Las categorías analíticas empleadas en la investigación de la interacción objeto de estudio están referidas a la comunicación de sentido, la moralidad y el poder, consideradas como elementos integrales de una interacción social, que implican respectivamente la aplicación de esquemas interpretativos, normas y medios o recursos, elementos que, en conjunto, constituyen las modalidades de la interacción (Giddens, 2001, pp. 129, 150). La práctica de producción de datos, en esta sección del documento, se abocó a la realización de entrevistas semiestructuradas con grupos focales para dar pauta a la incorporación de los discursos empleados en la interacción enseñanza-aprendizaje y a la inclusión de actores situados — los miembros del grupo de parentesco-como parte del contexto. Esta aproximación a la práctica de socialización de conocimientos se diferencia, entonces, de aquella que la aborda mediante el análisis de problemas semánticos vinculados a las competencias lingüísticas de hablantes individuales o al examen de las propiedades de actos del habla aislados (Giddens, 2011, p. 105). Otras prácticas de producción de datos efectuadas en el desarrollo de la investigación, realizada durante 2014 y 2015, se basaron en la elaboración de genealogías y representaciones de configuraciones de los espacios de residencia y productivos elaboradas por los grupos de parentesco, observación directa y diario de campo. La investigación se inscribe en la generalización analítica de los estudios de caso, que es distinta a la generalización estadística que se refiere a la "inferencia realizada a partir de una muestra estadísticamente representativa [...] en donde se trata de 
enumerar frecuencias" (Giménez, 2012, p. 49). La generalización analítica es un término acuñado por Yin (2009, p. 15), que se usa para designar la generalización de los estudios cualitativos, y apunta a una teoría del fenómeno estudiado que puede ser transferible a otros casos o refinada a la luz de ellos (Yin, 2009, pp. 37, 116). En esta dirección, la investigación plantea que el estudio de los procesos de socialización del conocimiento requiere de la indagación de cómo los grupos sociales - los pueblos indígenas - interpretan y realizan tales procesos a partir del uso de esquemas interpretativos que emplean en el habla, los cuales constituyen modos de prefiguración integrados en los reservorios de saber de los actores, que se aplican reflexivamente para el mantenimiento de una comunicación (Giddens, 2011, p. 65).

\section{LOS ESPACIOS DE RESIDENCIA Y PRODUCTIVOS \\ DE GRUPOS LOCALIZADOS DE PARENTESCO COMO ESCENARIOS DE SOCIALIZACIÓN DE CONOCIMIENTOS}

Berger y Luckman (1998, pp. 164, 170) consideran la socialización como un proceso de internalización de la realidad que inicia en la niñez y se desarrolla en el seno de la familia. A esta etapa la denominan socialización primaria, y en ella se construye el primer mundo del individuo. Subsecuente a esta etapa, la socialización secundaria se desarrolla a través de instituciones; por lo tanto, consiste en la internalización de submundos institucionales (Berger y Luckman, 1998, p. 172). Bender (1976, p. 502) menciona que no hay evidencia sólida de que la familia nuclear sea el más importante agente socializador en el proceso de socialización primaria, pues esta suele también ocurrir en unidades sociales más amplias. Alude al referente de proximidad como característica de los grupos corresidenciales, y agrega que la corresidencia implica una interacción recíproca entre sus miembros, que está en la base de la socialización de los niños. Estas referencias abordan el proceso de socialización desde la perspectiva de los tipos y los agentes involucrados en la socialización evidenciando la complejidad del proceso. Sin embargo, una mayor comprensión del proceso de socialización requiere incluir el análisis del contexto de interacción en que dicho proceso se realiza, lo cual posibilita la identificación del peso específico de los escenarios de interacción en este proceso y entender las situaciones de copresencia de actores situados. En consecuencia, se parte de considerar la socialización de conocimientos como una práctica o interacción social que tiene una duración temporal y un sitio determinado (Giddens, 2011, p. 144), y se propone explorar, en 
este apartado, el contexto de la práctica de socialización de conocimientos del café orgánico realizada por grupos de parentesco tseltales, referido a las propiedades de los espacios que intervienen como escenarios de esa interacción social. Más adelante se realiza una aproximación al proceso de socialización en cuestión.

Los grupos de parentesco de nuestro interés constituyen una unidad social formada por tres generaciones de lazo patrilineal: los padres, los hijos casados y su descendencia. ${ }^{2}$ Nutini $(1976$, p. 17) señala que esos grupos corresponden a linajes mínimos, grupos de poca profundidad genealógica, que en general tienen una unidad residencial en un área circunscrita. A esta unidad social se le denomina grupo localizado de parentesco (Robichaux, 2005, pp. 168, 172). Esta unidad de parentesco opera, entre otras prácticas sociales, las prácticas de residencia y herencia de la tierra bajo un patrón de principios patrilineales que inciden en la estructuración de los espacios donde el grupo vive y trabaja (Cervantes et al., 2017). Se concibe a este grupo de parentesco como un sistema de interacción social, en el que el sistema son "las relaciones reproducidas entre actores y colectividades organizadas como prácticas sociales regulares” (Giddens, 2011, p. 61), y las prácticas situadas de residencia patrilocal y herencia patrilineal, como interacciones sociales.

En la residencia patrilocal, los padres otorgan a sus hijos casados terrenos del vecindario donde ellos viven para que construyan sus casas. La práctica reproducida de residencia, vista como un proceso, configura espacialmente un complejo habitacional integrado por los emplazamientos de las viviendas de los grupos domésticos ${ }^{3}$ de los hijos, incluido el del miembro fundador del grupo. Este espacio lindado constituye el ámbito de residencia del grupo localizado de parentesco tseltal, a la vez que un ámbito de propiedad, al que se le denomina unidad de residencia (Cervantes et al., 2017). ${ }^{4}$ En el contexto de formas de apropiación del territorio asentadas en la propiedad colectiva de pueblos originarios, los límites externos de la unidad de residencia —el ámbito de propiedad del grupo—, al igual que los

\footnotetext{
2 Entre los investigadores que en un nivel empírico han analizado estos grupos de parentesco en la región alteña se tiene a Villa Rojas, 1992; Vogt, 1966; Collier, 1976.

3 Se usa el concepto de grupo doméstico para designar a la unidad social que habita una casa del complejo habitacional del grupo localizado de parentesco. El grupo doméstico puede estar constituido por una familia nuclear (padres e hijos) o extensa, y puede incluir otros miembros que no tengan lazos de parentesco. La corresidencia constituye un atributo destacado del grupo doméstico (Bender, 1976, pp. 493, 497), a diferencia del atributo de parentesco que caracteriza a la familia (Bender, 1976, p. 493; Laslet, 1972), y permite enfocar el carácter localizado de esta unidad social para realizar una aproximación a la expresión espacial de las prácticas de parentesco.

${ }^{4}$ La noción de ámbito de propiedad aquíse vincula con el concepto de apropiación que tiene como condición indispensable "una organización del espacio y un sentido de propiedad [... que implica] delimitación, lindes, separación entre dos trozos de espacio [... ya que] todo espacio social organizado está lindado" (George, 1985, p. 41).
} 
límites internos correspondientes a los espacios habitacionales usufructuados por los grupos domésticos independientes, no precisan de barreras físicas (bardas, alambres), porque son reconocidos por los miembros de la comunidad y del grupo. De esta manera, se configura un espacio colectivo de vida de tres generaciones de lazo patrilineal, que puede o no incluir a otros residentes, y que posibilita una constante interacción entre los miembros del grupo de diferente nivel generacional. La figura 1 muestra la representación que el grupo localizado de parentesco Tsetet, uno de los grupos objeto de estudio, ${ }^{5}$ tiene de su unidad de residencia. La figura incluye la genealogía del grupo que da cuenta de la composición de los grupos domésticos independientes que lo integran y que habitan cada casa del complejo habitacional.

El espacio lindado de la unidad de residencia se constituye en una sede o, en términos de Giddens (2011, p. 152), en el lugar de un amplio conglomerado de interacciones - en este caso, entre los miembros del grupo- en el curso de un día característico. La sede presenta diferentes usos del espacio que proveen, a la vez, escenarios de interacción (Giddens, 2011, p. 151). Así, en la unidad de residencia del grupo localizado de parentesco tseltal, el espacio íntimo está representado por la habitación o habitaciones que se usan para dormir, ubicadas en cada una de las casas que integran este complejo habitacional, las cuales son denominadas wayeval, que lo mismo se traduce como dormir que soñar. La cocina es designada en tseltal snail pasobil velil (la casa de la elaboración de la comida); por lo general, esta constituye una construcción rústica adyacente al wayeval, en donde se reúnen los miembros de cada grupo doméstico independiente para tomar los alimentos cotidianamente. Sin embargo, la mayor parte de las actividades cotidianas de los miembros del grupo de parentesco transcurren, en gran medida, en los escenarios de interacción constituidos por espacios abiertos, como son los patios de las casas de los grupos domésticos y las áreas arboladas aledañas a ellas, pues las casas se emplean principalmente para dormir o comer.

El espacio abierto, propiedad constante de los escenarios de interacción de los miembros del grupo localizado de parentesco, se expresa en la nomenclatura tseltal en el término jamalal, que sirve también para designar el espacio del patio

\footnotetext{
5 En el paraje tseltal la diferenciación interna y localización de los grupos localizados de parentesco se da con base en el topónimo ah k'ol (tierra arriba) o ah lan (tierra abajo) y al jol bil (cabeza de nombre) del grupo adquirido patrilinealmente. El jol bil de los grupos de parentesco objeto de estudio corresponden a los vocablos Tsetet y Jảas, cuyo significado es árbol cortado yárbol de zapote, respectivamente. El primer grupo se localiza en el paraje Kotolté y el segundo en Los Mangos. El paraje es la unidad de asentamiento indígena que sustenta un patrón de asentamiento disperso en el espacio alteño, el cual contrasta con la organización urbana del espacio de la Ciudad de San Cristóbal de Las Casas (Cervantes, 2006, pp.156, 162).
} 
Figura 1. Representación de LA Unidad de ResidenCia del GRUPo Localizado de Parentezco (GlP) TSETET Y genealogía del Grupo con los Grupos Domésticos

(GDS) INDEPENDIENTES Y MIEMBROS QUE LO INTEGRAN. COMUNIDAD KOTOLTÉ, TENejapa, Chiapas.
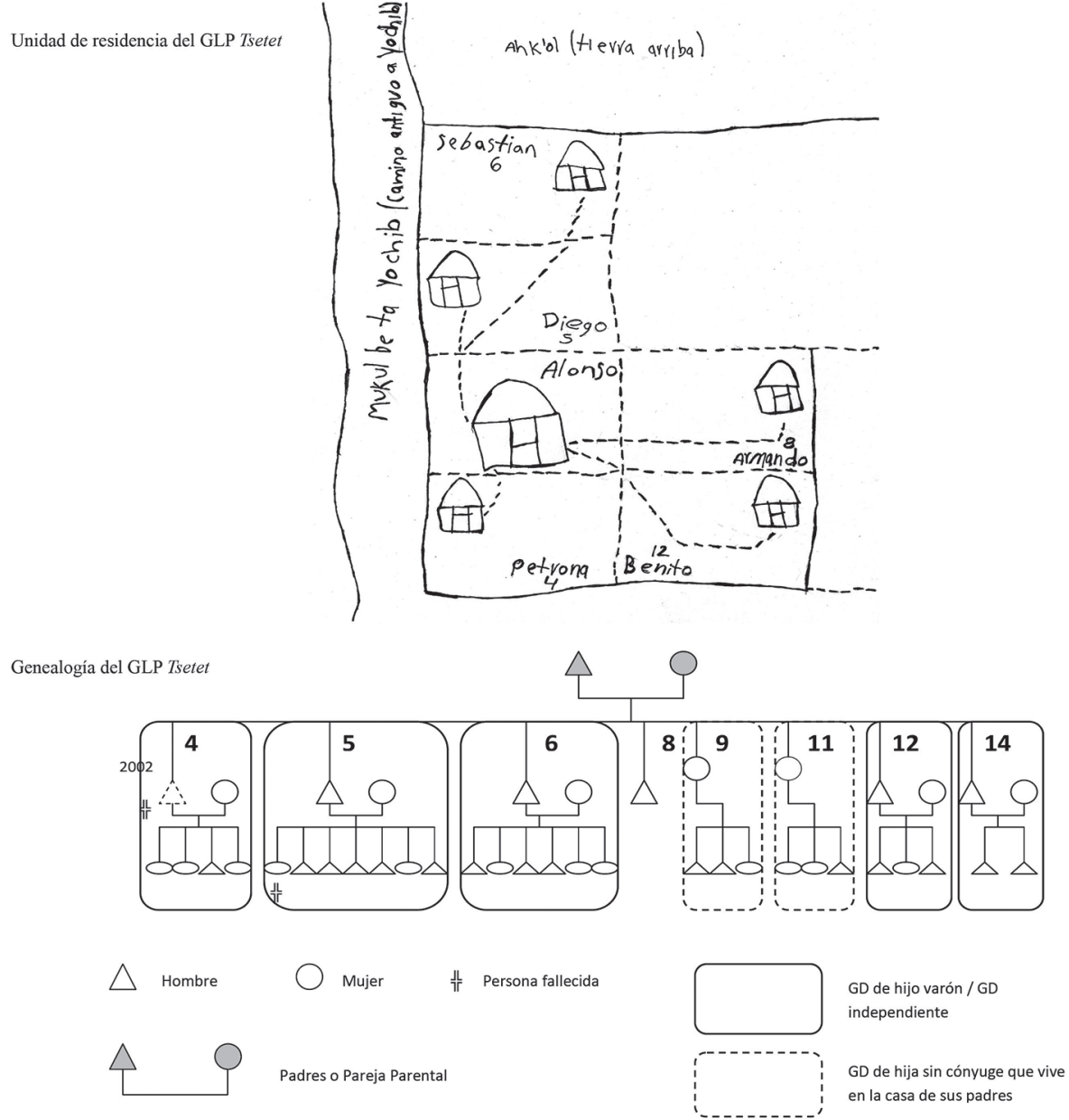

de la casa del grupo doméstico, el amak'. En los patios de las casas se descansa al término de las labores agrícolas, se seca el café obtenido en la cosecha por cada grupo doméstico, se platica de manera cotidiana mientras juegan los niños. De la distribución de encuentros cotidianos de los miembros del grupo de parentesco en el interior de la unidad de residencia destaca, en mayor número, la que ocurre 
en el amak' del abuelo, que así se constituye en el lugar de encuentro (tael bail) o lugar de reunión (tsob bail) de los miembros del grupo. Ahí ocurren con mayor sistematicidad circunstancias de copresencia que favorecen la comunicación cotidiana vinculada a la socialización de conocimientos, entre ellos, los relacionados con el café orgánico. La figura 2 muestra el esquema de la unidad de residencia del grupo localizado de parentesco Ja'as que fue elaborado por sus miembros. En esta representación, se traza el amak' como un articulador de los espacios habitacionales, y es el de mayor dimensión. La figura incluye la genealogía del grupo para dar cuenta de la composición de los grupos domésticos que lo integran y que habitan los distintos espacios del complejo habitacional.

La práctica de herencia patrilineal de la tierra conlleva a una parcelación del espacio productivo de la pareja parental del grupo localizado de parentesco paralela al usufructo de la parcela heredada por parte del grupo doméstico de cada hijo casado, en donde se sigue una estricta división en partes iguales del terreno a heredar entre los hijos para evitar conflictos en el interior del grupo. Este proceso de herencia sustenta la configuración de un terreno parcelado compacto que tiende a un mismo uso del suelo. Los límites de los territorios parcelarios de café orgánico de los grupos de parentesco y de las parcelas en su interior están demarcados por mojones apenas perceptibles, denominados en tseltal sakan, que dan la imagen, al observador externo, de una continuidad de áreas arboladas. Así, las prácticas reproducidas de parentesco en cuestión, vistas como procesos sociales, sustentan las formas espaciales de los ámbitos de residencia y productivo del grupo, sostenidas en la propiedad colectiva, que acusan regularidad y recurrencia en las comunidades cafetaleras alteñas. ${ }^{6}$

La figura 3 muestra el croquis del territorio parcelario de café orgánico del grupo de parentesco Tsetet y su estructura genealógica resultante de la práctica de la herencia patrilineal de la tierra. El territorio parcelario sustentado por las parcelas ya establecidas por parte del miembro fundador del grupo y los grupos domésticos de sus hijos (cuatro, cinco, seis y ocho) evidencia el peso específico de las relaciones de parentesco en la caficultura orgánica de la región alteña. La contigüidad de los minifundios de las plantaciones de café orgánico de los grupos domésticos que integran el grupo de parentesco y la ausencia de barreras físicas al interior de esta forma espacial permiten la libre movilidad de sus miembros y

${ }^{6}$ La conceptuación de la espacialidad de los procesos sociales que plantea Coraggio (1989, p. 86) señala, entre otras nociones, que una forma espacial es aquella configuración territorial que acusa regularidad y recurrencia, y su sentido puede ser descifrado a partir de la lógica del proceso social correspondiente. 
Figura 2. RepresentaCión de LA Unidad de RESIDENCIA DEl GRUPo LoCALIZAdo de Parentesco (GlP) Ja'As y genealogía del Grupo con los Grupos Domésticos (GDS) y miembros Que lo integran. Comunidad Los Mangos, Tenejapa, Chiapas.

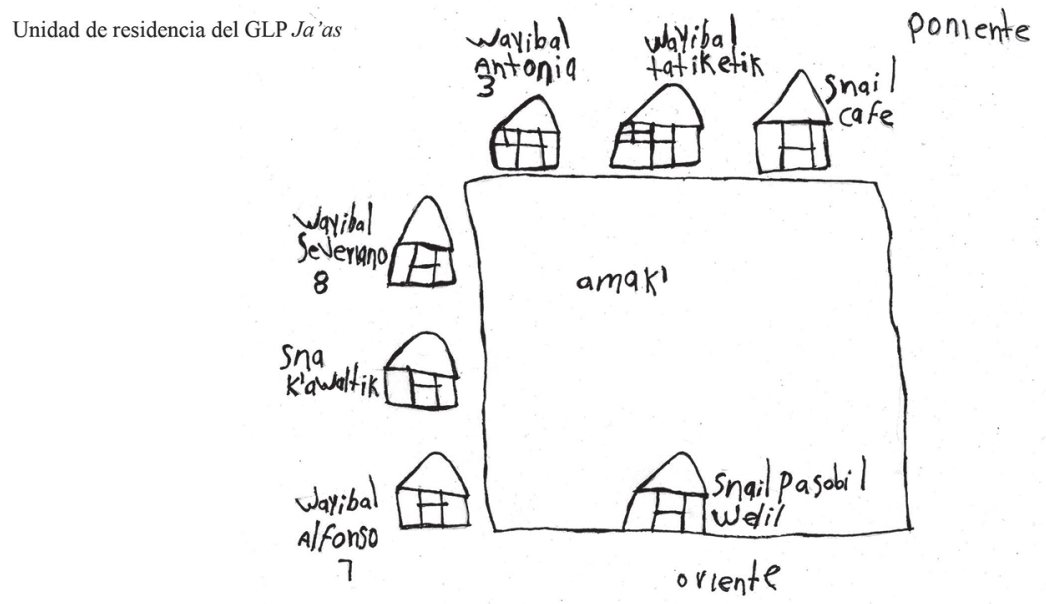

Genealogía del GLP Ja'as
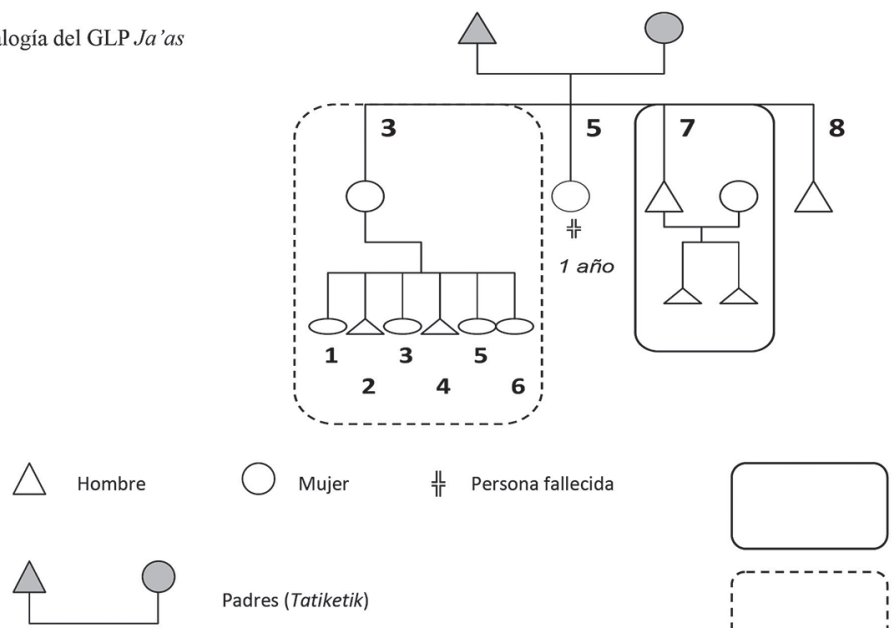

GD de hijo varón

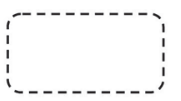

GD de hija sin cónyuge

posibilitan su constante interacción dentro de este espacio lindado. Esta configuración territorial alberga un espacio colectivo de vida del grupo y constituye una sede, esto es, siguiendo a Giddens (2011, p. 151), un lugar donde se intersecan las rutinas de encuentro de los miembros del grupo de parentesco relacionadas con 
Figura 3. Croquis del Territorio Parcelario de Café Orgánico (tPCO) del Grupo Localizado de Parentesco (GlP) TSETET y genealogía del Grupo con LOS GRUPos Domésticos (GDS) QUE HEREDARON PATRILINEALMENTE UNA PARCELA. Comunidad Kotolté, Tenejapa, Chiapas.

TPCO del GLP Tsetet
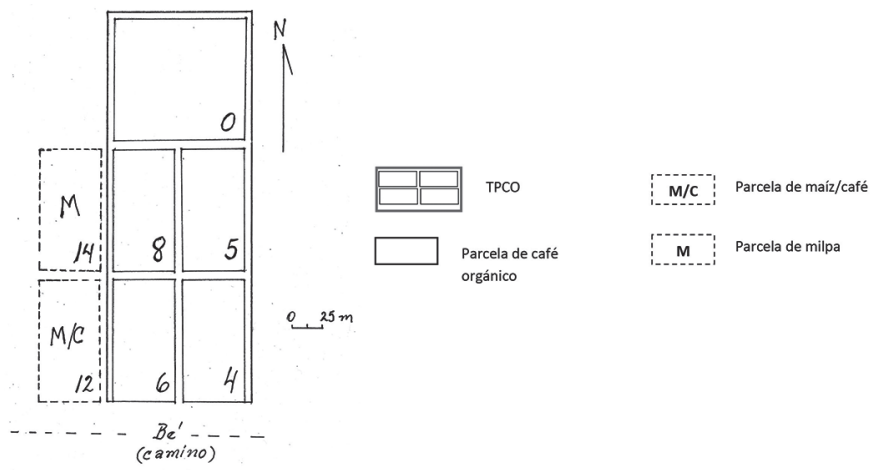

Distribución de parcelas heredadas por hijos varones y parcela del padre, ubicadas en $A h k$ 'ol (tierra arriba), aprox. a $1 \mathrm{~km}$ de la unidad de residencia del GLP Tsetet. Kotolté, Tenejapa, Chis.
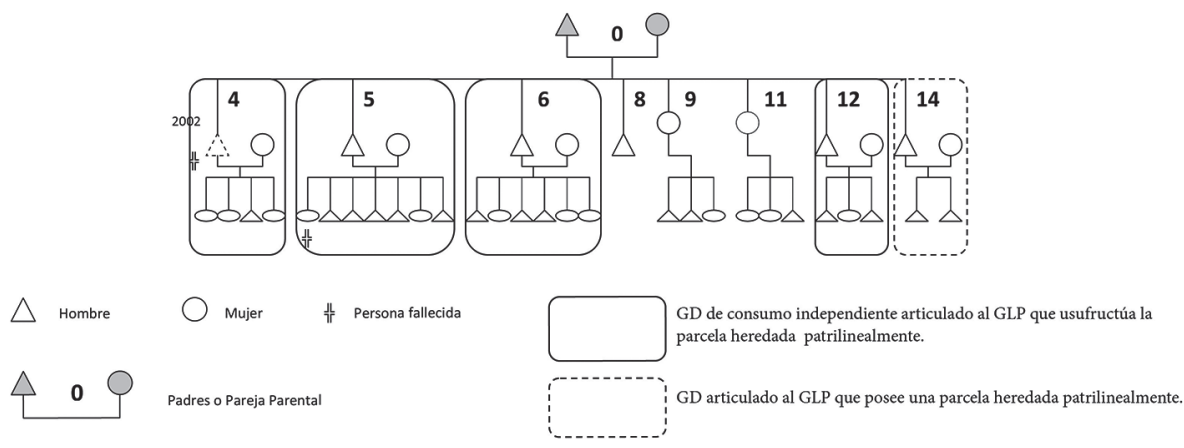

las prácticas del manejo del cultivo realizadas comúnmente por cada grupo doméstico conforme al itinerario técnico del ciclo agrícola del café. Esta sede, al igual que la sede de la unidad de residencia, interviene como parte del escenario de socialización de conocimientos del café orgánico y de la interacción enseñanzaaprendizaje de este tipo de conocimientos en el interior del grupo de parentesco, aspectos que se revisan en el siguiente apartado. 


\section{APROXIMACIÓN A LA PRÁCTICA DE SOCIALIZACIÓN DE CONOCIMIENTOS DEL CAFÉ ORGÁNICO DE GRUPOS LOCALIZADOS DE PARENTESCO TSELTALES}

Santoro $(2003$, p. 240) señala que en la orientación de cualquier acción social encontramos un conocimiento, "todo un conjunto de suposiciones, intuiciones, imágenes, conceptos y teorías que, en diferentes grados de elaboración y de abstracción, pretenden construir una imagen verdadera de lo social, acompañando y dotando de un significado la conducta de los sujetos en relación con la conducta de los otros". Por ello, la vida colectiva es un flujo continuo de conducta intencional gracias a la reflexividad del agente (Giddens, cit. en Lutz, 2010, p. 215), entendida como el conocimiento que los actores tienen de su acción y del contexto en el que se desarrolla (Giddens, 2011, p. 41).

Este apartado introduce a la comprensión de la práctica de socialización de conocimientos de café orgánico realizada por grupos localizados de parentesco tseltales. Para ello, se analizan los conceptos manipulados por los actores en los discursos producidos en la interacción enseñanza-aprendizaje de los conocimientos del café orgánico en el marco de un saber mutuo o conocimiento mutuo contextualizado en la cultura del grupo en cuestión. ${ }^{7}$ El agente, para funcionar en el mundo, debe poder interpretarlo, y tal posibilidad se sustenta en un saber mutuo (García, 2013, p. 261). El término saber mutuo (mutualknowledge) es acuñado por Giddens (2001, p. 132), y denota genéricamente el saber que se da por sentado, que los actores suponen que los otros poseen si son miembros competentes de la sociedad, y que se aprovecha para sostener una comunicación en interacción. El saber mutuo es aplicado a través del lenguaje en la forma de esquemas interpretativos para entender lo que otros dicen (say) y denotan (mean) (Giddens, 2001, p. 128).

En la interacción enseñanza-aprendizaje entre los miembros de los grupos localizados de parentesco tseltales Ja' as y Tsetet, los esquemas interpretativos usados tanto por el que enseña como por el que aprende refieren al mismo vocablo nopel, verbo que denota o significa acercar o hacer que otro se aproxime (Paoli, 1999, p.

\footnotetext{
La información recopilada que sirvió de base para el análisis propuesto se obtuvo a través de entrevistas semiestructuradas con grupos focales. Los grupos se conformaron bajo el supuesto de que la interacción enseñanzaaprendizaje definía límites precisos entre dos estratos generacionales del grupo localizado de parentesco, los grandes que enseñan y los menores (adolescentes y niños) que aprenden. Sin embargo, los datos empíricos apuntan en la dirección de que la interacción en cuestión frecuentemente tiende a realizarse de forma horizontal en el estrato de adolescentes y niños del grupo, como se verá más adelante.
} 
22). ${ }^{8}$ Así, quien enseña el trabajo de café orgánico dice ya yich ' noptesel a'tel orgánico (dar para hacer que otro se aproxime al trabajo orgánico); mientras quien aprende dice ya jnop a'tel orgánico (yo me acerco al trabajo orgánico). ${ }^{9}$ En consecuencia, las conductas del que enseña y del que aprende son reconstruidas en el interior del campo de sentido del verbo nopel, bajo la respectiva connotación de acercar al otro a saberes y haberes o de aproximarse a saberes y haberes, ambas acciones contextualizadas por los actores en su propia cultura. Enseñar en lengua tseltal sugiere el ejercicio de orientar y acompañar, y discrepa del sentido de la acción de transferir información que evoca este verbo tanto en otros contextos educativos como en la transferencia de innovaciones técnicas.

De esta manera, los esquemas interpretativos referidos a la palabra nopel, como parte de los cuerpos de conocimientos compartidos ${ }^{10}$ de hablantes de lengua tseltal, se aprovechan, siguiendo a Giddens (2001, p. 133), para crear y sostener contextos de una comunicación de enseñanza-aprendizaje en encuentros que ocurren en el ámbito de los espacios colectivos de vida del grupo, la unidad de residencia y el territorio parcelario del café orgánico. La sistematicidad en circunstancias de copresencia por parte de los miembros del grupo de parentesco involucrados en tales encuentros posibilita que el sentido de la palabra nopel, su significado, se aprehenda, como señala Wittgenstein (cit. en García, 2013, p. 270), en el examen de su empleo tanto por el actor que enseña como por el que aprende.

A la vez, la práctica social de enseñanza-aprendizaje sustentada en encuentros cotidianos o periódicos en las sedes ya mencionadas entraña a actores que, como Lutz (2010, p. 215) señala, comparten en ese momento una espacialidad de posición y una espacialidad de situación. En el contexto del grupo localizado de parentesco, la conducta de los actores en esos encuentros suele estar permeada por la situación que da el vínculo generacional entre padres e hijos e hijas. La relación jerárquica entre adultos y niños o adolescentes que revela este vínculo en la interacción enseñanza-aprendizaje está ligada al vocablo tseltal ch'un, que significa obedecer, esquema interpretativo que también denota la acción de comprender. Pero este vocablo comúnmente no se enuncia en los encuentros de enseñanza-aprendizaje en el grupo, ya que la conducta implícita en este vocablo forma parte de un tipo de

\footnotetext{
8 El vocablo utilizado para enseñar/aprender tiene igual raíz que las palabras nopoly nopoltic, usadas tanto en lengua tseltal como tsotsil para designar, respectivamente, "que algo está cerca" (adverbio de lugar) o "un lugar cercano" (sustantivo) (Instituto Nacional para la Educación de los Adultos, 2001; Delgaty y Ruiz, 1986).

9 La raíz del verbo nopel la encontramos en el vocablo tseltal nopteswanej, que significa maestro, "aquel quien tiene un oficio de aproximar al educando" (Paoli, 1999, p. 22).

10 Término usado por Gadamer (cit. en Giddens, 2011, p. 83).
} 
normas que, de acuerdo con Giddens (2011, p. 59), son aprendidas tácitamente por los actores, pero intervienen de forma decisiva en la producción y reproducción de las prácticas sociales. Esta norma, como parte de los medios culturales compartidos por los actores, se llega a plantear en un plano discursivo en forma de consejo en situaciones atípicas, cuando la conducta de un actor no se orienta a querer aprender, por ejemplo, las labores del cafetal orgánico.

Todo el trabajo que hacen los padres lo tienen que aprender los hijos... cuando no quieren [se refiere a sus hijos Alfonso y Severiano] ir a aprender el trabajo de orgánico (nop àtel orgánico), entonces me enojo y me voy solo al cafetal... cuando regreso del cafetal, les digo que tienen que obedecer, que si no quieren guardar en su corazón lo orgánico pues todo se va a perder... que si no van a trabajar, entonces no van a aprender (Diego Jảas Girón Gómez [59 años], miembro fundador del grupo de parentesco. Entrevista con el grupo de hombres del grupo localizado de parentesco tseltal Jảas, Los Mangos, Tenejapa, febrero de 2015).

En la interacción objeto de estudio, los esquemas de interpretación aplicados tanto en la comunicación como en las normas que la constituyen sustentan marcos de sentido. ${ }^{11}$ Giddens (2001, p. 120) señala que los marcos ofrecen una ordenación de actividades y de significados que permite a los actores la escenificación de rutinas diarias. Agrega que la creación de marcos "ocurre como mediación de actividades prácticas y en función de los diferenciales de poder que los actores son capaces de aportar" (Giddens, 2001, p. 140). Aquí la noción de poder representa la capacidad transformadora de la acción social, y se concreta en la movilización o el aporte de recursos aplicados como medios en la interacción, con lo cual se constituye el "puede" que media entre intenciones o necesidades (Giddens, 2001, pp. 137-138). En la interacción en estudio, el uso del poder está vinculado al agente que realiza la acción de enseñar, sujeta al interés de que el que aprende se apropie de conocimientos para realizar el trabajo del café orgánico. De ahí que la agencia sea una acción orientada a la praxis (Hernández, 2006, p. 6). ${ }^{12}$

11 Goffman (1986,pp. 21-22) señala que los marcos permiten a los individuos ubicar, percibir, identificar y etiquetar los acontecimientos ocurridos en su vida diaria. La importancia de la obra de Goffman, señala Giddens (2011, p. 72), reside en su preocupación por el ordenamiento temporal y espacial de una actividad social que refiere a condiciones de copresencia en encuentros sociales.

12 La acción social requiere tratarse como praxis, y no solo como sentido, esto es, verse a través del compromiso de los actores con la realización de práctica de intereses, incluida la transformación material de la naturaleza por la actividad humana (Giddens, 2001,p.73). Esta postura reconoce la centralidad del poder en la vida social (Giddens, 2001, p. 73). 
Los conocimientos que trasmite el agente son recursos de asignación, ${ }^{13}$ saberes aplicados vinculados con el proceso del trabajo agrícola del café en el nivel parcelario realizado comúnmente por cada grupo doméstico que integra el grupo localizado de parentesco. Las rutinas de encuentro de los grupos domésticos en la sede del territorio parcelario del café orgánico, conforme al desarrollo del itinerario técnico del ciclo agrícola del café, posibilitan momentos de interacción colectiva entre los miembros del grupo de parentesco, en donde la práctica de enseñanza-aprendizaje sucede en distintos grados entre miembros de diferentes niveles generacionales (adultos y adolescentes) y entre miembros del mismo nivel generacional o niveles contiguos (adolescentes y niños). En consecuencia, la agencia, en esta interacción, no es una propiedad exclusiva del miembro fundador del grupo localizado de parentesco o de los padres de cada núcleo familiar, ni la socialización de conocimientos del café orgánico es distintiva de la esfera del grupo doméstico. Los siguientes testimonios ilustran las relaciones que guardan cierta horizontalidad entre los miembros de los grupos Ja'as y Tsetet en la socialización de conocimientos del café orgánico, situación que propicia una mayor difusión de estos haberes y saberes. Estos testimonios también dan cuenta del proceso que entraña enseñar y aprender la complejidad del conjunto de prácticas que integran el itinerario técnico del ciclo de este cultivo.

Vemos el trabajo del tatik [se refiere a Diego, su papá], así hemos aprendido... Cuando mi papá no puede ir a la parcela de café, entonces vamos mi hermano Severiano y yo, junto con mis sobrinos Juan y Agustín... entre los cuatro hacemos podas; ${ }^{14}$ de más chicos [Juan y Agustín] no sabían hacer ese trabajo, aprendieron mirando lo que se está haciendo... asíhan ido aprendiendo a hacer otras cosas, a sembrar palo de agua ${ }^{15}$ para que no se pierda la tierra con la lluvia... (Alfonso Jảas Girón Pérez [24 años], entrevista con el grupo de jóvenesy adolescentes del grupo localizado de parentesco tseltal Jảas, Los Mangos, Tenejapa, febrero de 2015.)

13 Dentro de la tipología de recurso de asignación se encuentran los medios de producción/reproducción material en donde se incluye la tecnología (Giddens, 2011, p. 285). Bajo este enfoque, los conocimientos o saberes de café orgánico considerados como un elemento inherente a la tecnología de producción orgánica constituyen un recurso de asignación. La posesión del poder, señala Giddens (2001, p. 140), resulta de la destreza superior lingüística o dialéctica de una persona en la conversación con otra; de la posesión de tipos adecuados de saber técnico; de la movilización de la autoridad o la fuerza, etcétera. Lo que pasa por realidad social está en relación inmediata con la distribución del poder. En esa dirección, en la interacción enseñanza-aprendizaje de conocimientos del café orgánico, la agencia del que enseña se evidencia en la posesión de tipos adecuados del saber técnico del café orgánico.

${ }_{14}$ Labor del cafetal orgánico que consiste en el corte de ramas viejas que se realiza con machete para que crezcan ramas nuevas y frutos.

15 Práctica de manejo para la conservación de suelos, que consiste en sembrar arbustos conforme a curvas de nivel para aminorar el arrastre de suelo por lluvia. 
Las mujeres no saben podar... María aprendió lo del abono orgánico en la casa del tatik [padre] Alonso... ${ }^{16}$ Hay trabajos difíciles como el abono orgánico, que solo hacemos con el tatik [Diego, su padre], junto con ella [María]... el abono orgánico se hace aquí cerca de la casa... (Severiano Jảas Girón Pérez [21 años], entrevista con el grupo de jóvenes yadolescentes del grupo localizado de parentesco tseltal Jảas, Los Mangos, Tenejapa, febrero de 2015).

El mamil [abuelo] Alonso hace una abonera muy grande... sí, como se hace aquí en la casa aprendimos yo, Alonso, María Esther y Petrona [primos de David ${ }^{17}$ ] a hacer el abono orgánico... se hace aquí cerca del patio y vemos que le ponen a la abonera... le ponen abono de lombrices, cal, ceniza, tse mani [hierba de monte]... (David Tsetet López Pérez [16 años], entrevista con el grupo de adolescentes y niños del grupo localizado de parentesco tseltal Tsetet, Kotolté, Tenejapa, marzo de 2015).

[...] lo primero que aprenden los niños es a cortar el café, les enseñamos a escoger los granos de café rojos, los que están maduros... los más chiquitos solo van a jugar al cafetal... (Rosa Pérez Meza [36 años], entrevista con el grupo de mujeres del grupo localizado de parentesco tseltal Tsetet, Kotolté, Tenejapa, marzo de 2015).

Los conocimientos sobre el café orgánico que socializan los grupos localizados de parentesco tseltales objeto de estudio provienen de un conocimiento híbrido generado por un sistema de interacción social más amplio, que es la red de la organización cafetalera. El andamiaje social de la red revela una heterogeneidad de actores integrada por los delegados designados por los grupos de parentesco de las comunidades del área de influencia de la organización y por un equipo de profesionistas que acompaña el proceso de producción y comercialización colectiva del café orgánico que desarrolla la organización cafetalera. Este conocimiento híbrido se sustenta en los conocimientos que los actores son capaces de aportar, y evidencia la interdependencia de un conocimiento mesoamericano (el de los grupos localizados de parentesco) y un conocimiento gestionado por el equipo de profesionistas. La efectividad de este conocimiento se mide por el avance de la caficultura orgánica en el área de influencia geográfica de la organización social cafetalera.

16 El tatik (padre) Alonso Tsetet López es uno de los miembros fundadores de la organización cafetalera Kotolté. En el patio de su casa ocurren frecuentemente talleres de capacitación de café orgánico, a los que asisten miembros de los grupos de parentesco, este es el caso de María, sobrina de Severiano, de 18 años de edad.

17 Sus primos Alonso, María Esther y Petrona tienen 12, 12 y 13 años, respectivamente. 
El cuadro 1 resume los elementos que se aplican en la interacción enseñanzaaprendizaje de conocimientos acerca del café orgánico entre miembros del grupo localizado de parentesco tseltal. Sin embargo, la motivación o el interés que suscita la producción de café orgánico o la propia socialización de conocimientos de este cultivo por parte de los miembros de grupos de parentesco necesariamente tiene como referencia motivos que se inscriben en procesos más amplios:

Nuestro difunto abuelo nos dijo ich'al ta muk'ta alum kinal, eso quiere decir cuidar la tierra... la tierra es la que nos da de comer... por eso aprendimos el trabajo de café orgánico... (Alonso Tsetet López [70 años], miembro fundador del grupo de parentesco. Entrevista con el grupo de hombres del grupo localizado de parentesco tseltal Tsetet, Kotolté, Tenejapa, marzo de 2015.)

Cuando empezamos el trabajo de orgánico fue por el precio, porque los particulares, los coyotes no daban buen precio... con los talleres de orgánico me di cuenta que si se le echaba poxil ${ }^{18}$ al cultivo, mataba todas las plantas, por eso dejé de usarlo... al no usar químico todo crece, ahorita trabajo con puro orgánico... (Diego Jaas Girón Gómez [59 años], miembro fundador del grupo de parentesco. Entrevista con el grupo de hombres del grupo localizado de parentesco tseltal Jảas, Los Mangos, Tenejapa, febrero de 2015).

En el cafetal orgánico también crecen muchas plantas medicinales para curarnos, también hay árboles de fruta, plátano, naranja, lima, níspero... un cafetal bien cuidado da buena producción... (Alonso Tsetet López [70 años], entrevista con el grupo de hombres del grupo localizado deparentesco tseltal Tsetet, Kotolté, Tenejapa, marzo de 2015).

El trabajo que hacen los padres lo tienen que aprender los hijos... si se aprende el trabajo de orgánico, se pueden comprar sus cosas, sus zapatos... porque no solo en Estados Unidos o en México (la ciudad de México) hay trabajo, hay dinero... (Diego Jảas Girón Gómez [59 años], entrevista con el grupo de hombres del grupo localizado de parentesco tseltal Jáas, Los Mangos, Tenejapa, febrero de 2015).

Como refieren los testimonios, en estos procesos se encuentran intereses que van desde el ejercicio del cuidado de los recursos naturales bajo una noción mayance hasta la obtención de un mejor precio por la producción, comercializada de modo colectivo, que retribuya el trabajo campesino invertido en el cafetal e incida en la mejora de las condiciones de vida de quienes producen el café de manera orgánica. Los motivos también incluye mantener el cafetal orgánico como un policultivo ante la gran diversidad de recursos genéticos locales vinculados a las preferencias y

18 Término que significa veneno, que es utilizado para designar a los agroquímicos. 
CuAdro 1. ElEmentos de LA PRÁCTICA DE ENSEÑANZA-APRENDIZAJE DE

CONOCIMIENTOS DEL CAFÉ ORGÁNICO REALIZADA POR MIEMBROS DEL GRUPO

LOCALIZADO DE PARENTESCO TSELTAL

\begin{tabular}{|c|c|c|c|c|}
\hline & \multirow{2}{*}{$\begin{array}{l}\text { Propiedades de una } \\
\text { interacción social/ } \\
\text { modalidad }\end{array}$} & \multicolumn{3}{|c|}{ Interacción enseñanza-aprendizaje } \\
\hline & & $\begin{array}{l}\text { Esquema interpretativo } \\
\text { principal }\end{array}$ & El que enseña & El que aprende \\
\hline \multirow{3}{*}{ 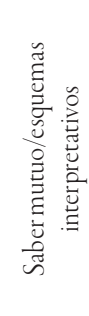 } & $\begin{array}{l}\text { Comunicación de } \\
\text { sentido/esquemas } \\
\text { interpretativos }\end{array}$ & Nopel & $\begin{array}{l}\text { Yaich'noptesel } \\
\text { dar para hacer que otro se } \\
\text { aproxime a... }\end{array}$ & $\begin{array}{l}\text { Ya jnop } \\
\text { acercarse a... }\end{array}$ \\
\hline & $\begin{array}{l}\text { Moralidad/ } \\
\text { Normas* }\end{array}$ & Chiun & & $\begin{array}{l}\text { jch'un } \\
\text { obedezco/comprendo }\end{array}$ \\
\hline & Poder/recursos ${ }^{* * *}$ & & $\begin{array}{l}\text {..tapasele te xposil kajpel } \\
\text {...hacer la medicina-abono } \\
\text { de café }\end{array}$ & \\
\hline
\end{tabular}

* Los esquemas interpretativos se expresan a través del lenguaje en la comunicación de sentido.

** Las normas son procedimientos de interacción que se aplican a la reproducción de prácticas sociales (Giddens, 2011, p. 57).

***Los conocimientos trasmitidos son recursos de asignación, a la vez que esquemas interpretativos que, al igual que los correspondientes a la comunicación y las normas, forman parte de categorías semánticas públicamente accesibles (Wittgenstein, cit. en Giddens, 2001, p. 72) al interior de un grupo social específico.

las necesidades culturales de la población, pues las especies presentes en él —aparte del café- responden a una diversidad de bienes y servicios relacionados con un patrón de usos alimenticios, ornamentales, condimenticios, medicinales, rituales, maderables, etcétera, del grupo doméstico. ${ }^{19}$ De ahí que todos estos referentes "están mediados por las relaciones sociales que los individuos mantienen en las prácticas de rutina de su vida diaria" (Giddens, 2011, p. 85).

\section{Encuentros y enseñanza-aprendizaje en el espacio colectivo del territorio parcelario de café orgánico del grupo localizado de parentesco}

Los miembros del grupo no se apropian de los conocimientos del café orgánico como algo ya dado, sino que, siguiendo a Giddens (2001, p. 133), son producidos y reproducidos de nuevo por ellos como parte de la continuidad de su vida, al estar vinculados a rutinas de encuentro ciclo a ciclo cafetalero en el ámbito del espacio colectivo de vida del territorio parcelario de café orgánico - y en menor medida, de la unidad de residencia-.

19 Así lo ejemplifica el inventario de una parcela de un cuarto de hectárea de cafetal orgánico en la comunidad de Polhó, Chenalhó, Chiapas, que reporta 45 especies diferentes al café (Pérez Grovas, 1999, p. 48). 
Figura 4. Segmento del Grupo Localizado de Parentesco (Glp) Tsetet Que PARTICIPÓ EN LA LABOR DE CULTIVO DE CONSERVACIÓN DE SUELOS (SIEMBRA DE PALO DE AGUA, MAYO 2014) DE CICLO CAFETALERO 2014-2015 REALIZADA EN LA PARCELA DE LOS abuelos, ubicada en el Territorio Parcelario de Café Orgánico (TPCO) del

Grupo. Comunidad Kotolté, Tenejapa, Chiapas.

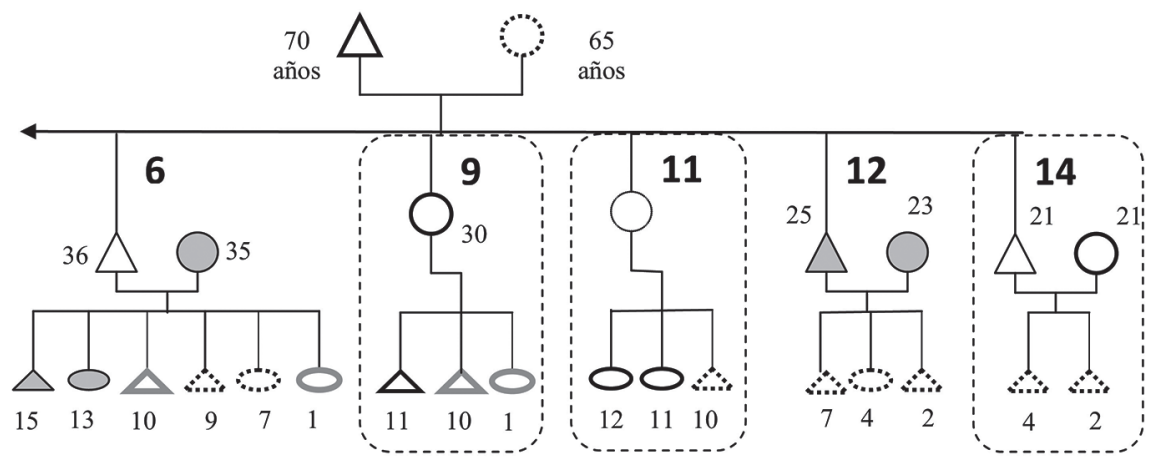

\footnotetext{
$\triangle \bigcirc$ Miembros de Grupos Domésticos (GDs) -mujeres, hombres, adolescentes- que participaron en la labor de cultivo con remuneración económica por parte del abuelo $\triangle \bigcirc \begin{aligned} & \text { Miembros de GDs - mujeres, hombres, adolescentes y } \\ & \text { niños- que participaron en la labor de cultivo sin }\end{aligned}$ remuneración económica

$\triangle \bigcirc$ Niños de GDs que cuidaron a bebés durante la labor de cultivo

$\therefore \quad$ Niñas y niños de GDs y abuela que permanecieron en las viviendas de la unidad de residencia del GLP Tsetet
}

Miembros hombres de GDs que durante la labor de cultivo estuvieron en la cabecera municipal de Tenejapa, Chiapas, realizando otras actividades

$\triangle$ Hombre $\bigcirc$ Mujer

La figura 4 ilustra la fracción del grupo localizado de parentesco Tsetet que participó en la labor de cultivo de conservación de suelos (siembra de palo de agua, mayo de 2014) del ciclo cafetalero 2014-2015 en la parcela de los abuelos. Durante el desarrollo de la labor de cultivo en cuestión, los momentos de interacción colectiva, que ocurren en distinto grado entre actores de diferentes niveles generacionales (el abuelo, el tío, las mujeres madres y los adolescentes o los niños) o entre actores del mismo nivel generacional (las y los adolescentes y los niños) que integran esta fracción del grupo, coadyuvan a que se realice la práctica de enseñanza-aprendizaje de la labor de cultivo.

Segmentos del grupo de parentesco (tal como lo evidencia la figura) o, en su caso, miembros de los grupos domésticos que articulan el grupo mantendrán rutinas 
de encuentro predecibles en la sede del territorio parcelario de café orgánico en el contexto del itinerario técnico del ciclo agrícola de este cultivo. Sin embargo, el carácter rutinizado de las sendas de vida de los miembros del grupo localizado de parentesco en esta sede no ocurre casualmente, sino que, como señala Giddens (2011, p. 98), se lo hace ocurrir por los modos de registro reflexivo de una acción (la enseñanza-aprendizaje de la práctica del manejo o la realización de la propia práctica del manejo) que los miembros del grupo sostienen en circunstancias de copresencia.

La noción de trabajo reflejada en el lenguaje empleado en las rutinas de encuentro de los miembros del grupo de parentesco en la sede del territorio parcelario del café no está anclada a una conducta que haga referencia a él como una situación obligatoria. Este matiz se evidencia, en mayor medida, en los discursos de las mujeres tseltales monolingües.

...con un solo corazón vamos a trabajar (junax ko 'tantik a'telotik) en la parcela de café que está tierra abajo (kajpetal lum ta Ah lan), vamos las mujeres a sembrar palo de agua, a la cosecha de café... los niños van con nosotras... (Antonia Jảas Girón Pérez [37 años], entrevista con el grupo de mujeres del grupo localizado de parentesco tseltal Jảas, Los Mangos, Tenejapa, febrero de 2015).

...cuando vamos a trabajar hay armonía (ay slamal kinal), vamos a hacer los trabajos del café, vamos a poner abono a las matas de café, ayudamos a limpiar el terreno... (Mariana Tsetet López [30 años], entrevista con el grupo de mujeres del grupo localizado de parentesco tseltal Tsetet, Kotolté, Tenejapa, marzo de 2015).

El lenguaje, como conciencia práctica ${ }^{20}$ que se expresa sobre el trabajo en estos testimonios, no se asienta en intereses divergentes en el interior de esta unidad social vinculados, por ejemplo, con aquellos relacionados con la división entre el capital y el trabajo asalariado, o con un conflicto de clases sociales, que es endémico en la sociedad capitalista. La tesitura de la noción de trabajo tseltal está fincada en una praxis ligada a la acción colectiva en concordia con los ritmos que manifiesta la vida.

Giddens (2011, p. 106) destaca la importancia de los encuentros fugaces en el marco de una rutina de encuentros como elemento central enlazado a una reproducción social. ${ }^{21}$ En nuestro caso de estudio, la rutina de encuentros que acontece en la sede del territorio parcelario de café orgánico, que los miembros del grupo

20 "el lenguaje es conciencia práctica", dijo Marx (cit. en Giddens, 2001, p. 125).

21 El proceso de reproducción comienza con la reproducción de las circunstancias materiales de la existencia humana y depende de ella la reprocreación de la especie y la transformación de la naturaleza (Giddens, 2001, p. 127). 
localizado de parentesco mantienen desde la niñez hasta la adolescencia o la edad adulta, hace posible la paulatina concatenación de los elementos que integran el itinerario técnico del ciclo agrícola del café orgánico, su cabal conceptuación en el contexto de la cultura tseltal y su reproducción. La importancia de la sede en cuestión, con las propiedades ya señaladas, reside en que provee escenarios de interacción social que favorecen procesos de intercambio y de transmisión de conocimientos del trabajo agrícola entre distintos niveles generacionales, en el marco de un saber mutuo contextualizado en la cultura tseltal. En términos generales, estos procesos se encuentran en la base de la continuidad de las formas del manejo agrícola, del mantenimiento de las calidades de la tierra y de la vigencia de los conocimientos en la región alteña. La enseñanza-aprendizaje de conocimientos acerca del café orgánico en el contexto del pueblo tseltal se puede considerar como una forma de acompañamiento que, aunado al uso de sedes colectivas por parte del grupo localizado de parentesco, al hecho de que esta unidad social agrupa a un conjunto de grupos domésticos, y a que esta interacción suele darse de manera horizontal en el interior del grupo, propicia una amplia difusión de la caficultura orgánica en el área cafetalera tseltal de la región de Los Altos de Chiapas.

\section{Conclusiones}

En la socialización de conocimientos del café orgánico realizada por grupos localizados de parentesco tseltales adscritos a una organización social cafetalera reviste importancia el contexto de interacción colectiva en que esta práctica se realiza, el cual remite a la constitución del Grupo, integrado por tres generaciones de lazo patrilineal, y a las sedes colectivas en donde sus miembros interactúan de manera cotidiana o periódica: la unidad de residencia y el territorio parcelario de café orgánico. Tal contexto de interacción se diferencia de escenarios en los que la socialización de conocimientos de este cultivo se efectúa en sedes constituidas por espacios compartimentados y en un nivel atomizado por la familia nuclear.

Las formas espaciales de la unidad de residencia y del territorio parcelario compacto que tiende a un mismo uso del suelo están sustentadas por las prácticas reproducidas de parentesco de la residencia patrilocal y la herencia patrilineal de la tierra que opera el grupo doméstico fundador del grupo, generación tras generación. Ambas formas espaciales constituyen ámbitos de propiedad del grupo localizado de

parentesco, cuyos límites internos no precisan de barreras físicas, dado el contexto 
de propiedad colectiva de pueblos originarios en que se insertan. Se considera que esta reproducción de prácticas de parentesco se asienta, como señala Voss (2015, pp. 39-40), en una noción de tiempo basada en que un hecho se repite periódicamente dentro de una secuencia infinita de ciclos consecutivos. Los cambios son manifestaciones de estos ciclos en que los acontecimientos se hacen, deshacen y rehacen (Puech, 1958, cit. en Voss, 2015, pp. 39-40). Esta forma específica de reproducción social de grupos domésticos se vincula más con un sentido de sustentabilidad y equidad in vivo, al ofrecer a la generación presente —es decir, a los hijos casados y su descendencia - un lugar donde vivir y donde trabajar, que con una prospectiva que responda a una noción de sustentabilidad fincada en el horizonte de un futuro o a una visión lineal de tiempo en la que se basa el desarrollo. Las prácticas de parentesco patrilineales señaladas, consideradas como procesos sociales, constituyen, a la vez, un principio de organización del territorio de los asentamientos indígenas. Asimismo, el grupo localizado de parentesco es una unidad socio-territorial ubicada entre el grupo doméstico y la comunidad, cuyas prácticas evidencian la agencia de un actor reflexivo con un carácter electivo de una forma de vida.

Siguiendo a Giddens (2011, pp. 151-152), estimamos que la unidad de residencia y el territorio parcelario de café orgánico son sedes colectivas, es decir, lugares donde se intersecan las rutinas de encuentro de los miembros del grupo relacionadas con los procesos de comunicación lingüística y el trabajo agrícola. Las sedes colectivas presentan diferentes usos del espacio que proveen, a la vez, escenarios de interacción. Entre estos escenarios se encuentran aquellos relacionados con la socialización de conocimientos, que se distinguen por ser espacios abiertos, por lo que en ellos ocurre con mayor sistematicidad, circunstancias de copresencia entre miembros del grupo de parentesco de diferentes niveles generacionales que favorecen la interacción enseñanza-aprendizaje de múltiples conocimientos, entre ellos los del café orgánico. La socialización de conocimientos implica el uso de esquemas interpretativos que se emplean en el habla, en el marco de un saber mutuo contextualizado en la cultura tseltal. En la interacción enseñanza-aprendizaje, que ocurre en encuentros cotidianos o periódicos entre los miembros del grupo, los esquemas interpretativos usados en la comunicación de sentido, tanto por el que enseña como por el que aprende, refieren al mismo vocablo nopel, verbo que denota o significa acercar o hacer que otro se aproxime (Paoli, 1999, p. 22). En lengua tseltal, enseñar sugiere el ejercicio de orientar y acompañar, y discrepa del sentido de la acción de transferir información que evoca este verbo tanto en otros contextos educativos como en la transferencia de innovaciones técnicas. Entre 
los conceptos usados por cualquier miembro del grupo localizado de parentesco en el aprendizaje de todo tipo de labor de cultivo se encuentran las expresiones ya jnop a'tel (yo aprendo trabajando), ya jnop ta pasele (yo aprendo haciendo) y ya jnop te kil ta pasele (yo aprendo mirando lo que se hace). Tales construcciones expresan formas de aprendizaje diametralmente opuestas al aprendizaje basado en la memorización de datos que se acostumbra realizar por parte de niños y adolescentes en las aulas de cualquier escuela en México. La realización de encuentros cotidianos o periódicos de enseñanza-aprendizaje de conocimientos del café orgánico en el grupo localizado de parentesco no requiere de un nopteswanej (maestro), "aquel quien tiene un oficio de aproximar al educando" (Paoli, 1999, p. 22), ni la enseñanza es coto exclusivo del anciano o sabio del grupo, ya que la agencia en esa interacción puede ser ejercida por las mujeres o los adolescentes miembros del grupo al trasmitir a otros esos conocimientos en distinto grado. En esa dirección, la agencia del que enseña se evidencia en la posesión de tipos adecuados de saber técnico de café orgánico.

La regularidad y la recurrencia de las formas espaciales de las sedes colectivas del grupo localizado de parentesco en el territorio comunitario y regional propician espacios informales de enseñanza-aprendizaje que coadyuvan a una difusión amplia de conocimientos del trabajo agrícola en las comunidades indígenas de la región, como ha sido en el caso de la caficultura orgánica en el área tseltal cafetalera. Justamente, los procesos de intercambio y de transmisión de conocimientos del trabajo agrícola que ocurren inter e intra generacionalmente entre los miembros del grupo en la sede colectiva del territorio parcelario son los que se encuentran en la base de la continuidad de las formas del manejo agrícola, del mantenimiento de las calidades de la tierra y de la vigencia de conocimientos, generación tras generación. En este punto destaca un elemento de continuidad en la actividad agrícola de las comunidades indígenas como es el policultivo. Pese a ser una especie introducida, el cafetal orgánico ha adquirido la misma lógica mesoamericana que la milpa al establecerse como policultivo y rescatar una gran diversidad de recursos genéticos locales vinculados a las preferencias y las necesidades culturales del grupo doméstico, pues las especies presentes en él —aparte del café- responden a una diversidad de bienes y servicios ligados a un patrón de usos alimenticios, ornamentales, condimenticios, medicinales, rituales, maderables, etcétera. López Austin (1995, p. 217) señala la existencia de un complejo articulado de elementos culturales en la tradición mesoamericana sumamente resistentes al cambio, que denomina el núcleo duro, cuya base reside en un núcleo agrícola. Aunque este autor 
asienta el concepto de núcleo duro en la cosmovisión indígena, la descripción de su funcionamiento "como gran ordenador [que] ubica los elementos adquiridos en la armazón tradicional y da sentido a lo novedoso -incluso un sentido profundo y complejo- reinterpretándolo para su ajuste” (López, 2001, p. 61), bien puede aplicarse a la práctica del policultivo en la plantación del cafetal orgánico. En el sureste del país, organizaciones campesinas e indígenas que producen café orgánico han promovido el policultivo en el establecimiento de cafetales, lo cual ha sustituido el esquema institucionalizado del monocultivo de café bajo la sombra monoespecífica impuesto por Inmecafé en el marco de la revolución verde (Pérez Grovas, 1998, pp. 43, 47).

En la lógica social y económica de los grupos domésticos campesinos e indígenas de las áreas cafetaleras, el trabajo se articula a los ciclos productivos de la milpa y el café con el fin de obtener valores de uso y valores de cambio, respectivamente, usándose estos últimos para adquirir satisfactores que no se producen. El cafetal orgánico parece presentar una contradicción por tratarse de un cultivo comercial, ya que en una parcela de un cuarto de hectárea se han reportado hasta 45 especies distintas del café (Pérez Grovas, 1999, p. 48), y la lógica comercial tradicional señala que se requiere establecer el mayor número de matas de café por unidad de superficie para alcanzar una productividad elevada de la especie. La paradoja se resuelve al ubicarse en una óptica de relaciones equitativas establecidas en el comercio justo, que postula la valoración del trabajo campesino, ingresos dignos y el cuidado medioambiental, es decir, si se rompe la inercia de una relación comercial basada en el costo-beneficio que abstrae los postulados mencionados.

Los procesos de socialización de conocimientos del café orgánico que realizan los grupos localizados de parentesco adscritos a las organizaciones cafetaleras tienen un gran peso específico en la difusión de este cultivo en las áreas cafetaleras. Aquí es importante considerar el señalamiento que hace Nutini (1996, p. 84) acerca de aportar elementos a la vinculación poco conocida entre parentesco y asociaciones voluntarias - considerando la organización cafetalera como tal-. Aunque esta vinculación puede existir en organizaciones sociales de campesinos indígenas que producen maíz, caña, etcétera, los mecanismos sociales en su interior responden generalmente a demandas gremiales. Mientras que los mecanismos sociales - entre los que se hallan las redes sociales - que han creado las organizaciones cafetaleras indígenas pueden sustentar, entre otros procesos, aquellos relacionados con la generación y la difusión de conocimientos que hacen posible el mantenimiento y la ampliación de este cultivo; de ahíla importancia de abordar en estudios posteriores los mecanismos 
sociales que sustentan la producción de café orgánico en México. El vínculo entre los grupos localizados de parentesco y los andamiajes sociales de la organización cafetalera evidencian el dinamismo de las relaciones de parentesco, que no suele ser visible para algunos enfoques antropológicos que las constriñen a un tratamiento normativo.

\section{BiBLIOGRAFÍA}

Bender, D. R. (1976). A Refinement of the Concept of Household: Families, CoResidence, and Domestic Functions. American Anthropologist, 69(5): 493-504. DOI: 10.1525/aa.1967.69.5.02a00050.

Berger, P., y Luckman, T. (1998). La construcción social de la realidad. Buenos Aires, Argentina: Amorrortu Editores.

Boege, E. (2008). El patrimonio biocultural de los pueblos indígenas de México. Hacia la conservación in situ de la biodiversidad y agrodiversidad en los territorios indigenas. Distrito Federal, México: Instituto Nacional de Antropología e Historia, Comisión Nacional para el Desarrollo de los Pueblos Indígenas.

Cervantes Trejo, E. (2006). Niveles de organización territorial de San Juan Chamula. En F. Anta, A. Arreola, M. A. González y J. Acosta (comps.). Ordenamiento territorial comunitario: Un debate de la sociedad civil hacia la construcción de politicas públicas (pp. 151-168). Distrito Federal, México: Secretaría de Medio Ambiente y Recursos Naturales, Instituto Nacional de Ecología, Instituto para el Desarrollo Sustentable en Mesoamérica, Grupo Autónomo para la Investigación Ambiental, Grupo de Estudios Ambientales, Methodus Consultora, Servicios Alternativos para la Educación y el Desarrollo.

Cervantes Trejo, E.; Estrada Lugo, E. I. J., y Bello Baltazar, E. (2017). Prácticas de parentesco y configuración de espacios colectivos de vida en el área tseltal cafetalera, Tenejapa, Chiapas. Relaciones. Estudios de Historia y Sociedad, 38(150): 281-315. DOI: 10.24901/rehs.v38i150.304.

Collier, G. A. (1976). Planos de interacción del mundo tzotzil. Bases ecológicas de la tradición en Los Altos de Chiapas. Distrito Federal, México: Instituto Nacional Indigenista, Secretaría de Educación Pública.

Coraggio, J. L. (1989). Sobre la espacialidad social y el concepto de región. En J. L. Coraggio, A. F. Sabaté y O. Colman (eds.). La cuestión regional en América Latina (pp. 67-106). Quito, Ecuador: Ediciones Ciudad. Recuperado de http://www. 
coraggioeconomia.org/jlc/archivos\%20para\%20descargar/Espacialidad\%20 social\%20y\%20el\%20concepto\%20de\%20región.pdf.

Delgaty, A., y Ruiz Sánchez, A. (1986). Diccionario tzotzil de San Andrés con variaciones dialectales tzotzil-español, español-tzotzil. Distrito Federal, México: Instituto Lingüístico de Verano.

Instituto Nacional para la Educación de los Adultos (2001). Diccionario básico de la lengua tzeltal. Distrito Federal, México: Instituto Nacional para la Educación de los Adultos, Secretaría de Educación Pública.

García Andrade, A. (2013) Giddens y Lubmann. ¿Opuestos o complementarios? Distrito Federal, México: Universidad Autónoma Metropolitana-Azcapotzalco, División de Ciencias Sociales y Humanidades.

George, P. (1985). La acción del hombre y el medio geográfico. Barcelona, España: Península.

Giddens, A. (2001). Las nuevas reglas del método sociológico: Critica positiva de las sociologías comprensivas. Trad. Salomón Merener. Buenos Aires, Argentina: Amorrortu Editores.

Giddens, A. (2011). La constitución de la sociedad: Bases para la teoría de la estructuración. Trad. José Luis Etcheverry. Buenos Aires, Argentina: Amorrortu Editores.

GiménEZ, G. (2012). El problema de la generalización en los estudios de caso. Cultura y Representaciones Sociales, 7(13): 40-62. Recuperado de http://www.scielo.org. $\mathrm{mx} / \mathrm{pdf} / \mathrm{crs} / \mathrm{v} 7 \mathrm{n} 13 / \mathrm{v} 7 \mathrm{n} 13 \mathrm{a} 2 . \mathrm{pdf}$.

Goffman, E. (1986). Frame Analysis: An Essay on The Organization of Experience. Boston, Massachusetts, Estados Unidos: Northeastern University Press.

Hernández Veráztica, A. E. (2006). La impronta práctica para la formulación de sentido. Iberóforum. Revista de Ciencias Sociales de la Universidad Iberoamericana, I(II): 1-17. Recuperado de http://www.ibero.mx/iberoforum/2/pdf/america_hernandez.pdf.

Ixtacuy López, O.; Estrada Lugo, E. I. J., y Parra Vázquez, M. R. (2006). Organización social en la apropiación del territorio: Santa Marta, Chenalhó, Chiapas. Relaciones. Estudios de Historia y Sociedad, XXVII(106): 183-219. Recuperado de http://www. colmich.edu.mx/relaciones25/files/revistas/106/pdf/OctavioIxtacuyLopez.pdf.

Laslett, P. (1972). Introduction: The History of the Family. En P. Laslett y R. Wall (eds.). Household and Family in Past Times Publications (pp. 1-90). Cambridge, Reino Unido: The Cambridge University Press.

López Austin, A. (1995). Tras un método de estudio comparativo entre las cosmovisiones mesoamericana y andina a partir de sus mitologías. Anales de Antropología, 
32(1): 209-240. Recuperado de http://www.revistas.unam.mx/index.php/antropologia/article/view/349/333.

López Austin, A. (2001). El núcleo duro, la cosmovisión y la tradición mesoamericana. En J. Broda y F. Báez Jorge (coords.). Cosmovisión, rituale identidad de lospueblos indigenas de México (pp. 47-65). Distrito Federal, México: Consejo Nacional para la Cultura y las Artes, Fondo de Cultura Económica.

Lutz, B. (2010). La acción social en la teoría sociológica: Una aproximación. Argumentos, 23(64): 199-218. Recuperado de http://www.redalyc.org/articulo. oa?id=59518491009.

MATA, B. (2003). Innovación tecnológica con participación de agricultores. En B. Mata García (ed.). Desarrollo tecnológico participativo para una agricultura sustentable (pp. 65-104). Chapingo, Texcoco de Mora, México: Universidad Autónoma Chapingo.

Moguel, P., y Toledo, V. M. (1999). Café, luchas indígenas y sostenibilidad: El caso de México. Ecología Politica, 18: 23-36. Recuperado de http://www.jstor.org/ stable/20743031.

Nolasco, M. (1985). Café y sociedad en México. Distrito Federal, México: Centro de Ecodesarrollo.

Nutini, H. (1976). Introduction: The Nature and Treatment of Kinship in Mesoamerica. En H. Nutini, P. Carrasco y J. Taggart (eds.). Essays on Mexican Kinship (pp. 3-77). Pittsburgh, Pensilvania, Estados Unidos: University of Pittsburgh Press.

Nutini, H. (1996). Mesoamerican Community Organization: Preliminary Remarks. Ethnology, 35(2): 81-92. Special Issue: Mesoamerican Community Organization: Barrios and Other Customary Social Units: Part I. Recuperado de http://www. jstor.org/stable/3774071.

Paoli Bolio, A. (1999). Educación y solidaridad en la pequeña comunidad tseltal. Guatemala, Guatemala: Coban, A.V.: Ak'Kutan, Centro Bartolomé de Las Casas.

Pérez Grovas Garza, V. (1998). Evaluación de la sustentabilidad del sistema de producción de café orgánico en la Unión de Ejidos Majomut en la región de Los Altos de Chiapas (tesis de Maestría). Universidad Autónoma Chapingo, Chapingo, Texcoco de Mora, México.

Pérez Grovas Garza, V. (1999). Café orgánico. Revista Pronatura, 5: 46-49.

Pérez Grovas Garza, V.; Cervantes, E.; Burstein, J.; Carlsen, L., y Hernández Navarro, L. (2002). El café en México, Centroamérica y el Caribe. Una salida sustentable a la crisis. Distrito Federal, México: Coordinadora Nacional de Organizaciones Cafetaleras, Coordinadora de Pequeños Productores de Café de Chiapas. 
Robichaux, D. (2005). Principios patrilineales en un sistema bilateral de parentesco: Residencia, herencia y sistema familiar mesoamericano. En D. Robichaux (comp.). Familia y parentesco en México y Mesoamérica: Unas miradas antropológicas (pp. 167-272). Distrito Federal, México: Universidad Iberoamericana.

SAntoro, P. (2003). El momento etnográfico: Giddens, Garfinkel y los problemas de la etnosociología. Reis. Revista Española de Investigaciones Sociológicas, 103(3): 239-255. Recuperado de http://www.reis.cis.es/REIS/PDF/REIS_103_101167997682011. pdf.

Villa Rojas, A. (1992). Parentesco y nahualismo en una comunidad tzeltal del sureste de México. En V. M. Esponda, S. Pincemin y M. Rosas (comps.). Antropología mesoamericana (pp. 73-90). Tuxtla Gutiérrez, Chiapas, México: Gobierno del Estado de Chiapas, Consejo Estatal de Fomento a la Investigación y Difusión de la Cultura, Sistema Estatal para el Desarrollo Integral de la Familia-Chiapas, Instituto Chiapaneco de Cultura.

Vogt, E. Z. (1966). Los zinacantecos, un pueblo tzotzil de los altos de Chiapas. Distrito Federal, México: Instituto Nacional Indigenista.

Voss, A. W. (2015). La noción del tiempo en la cultura maya prehispánica. LiminaR. Estudios Sociales y Humanisticos, 13(2): 38-52. Recuperado de http://liminar. cesmeca.mx/index.php/r1/article/view/391/403.

YIN, R. K. (2009). Case Study Research. Londres, Reino Unido: Sage. 